\title{
Study on group intervention regarding interpersonal trust among college students with campus psychodrama
}

\author{
Ying $\mathrm{Ge}^{1^{*}}$, Huamin $\mathrm{He}^{1}$, Linna Dai ${ }^{1,2}$ \\ ${ }^{1}$ School of Educational Science, Laboratory of Cognition and Mental Health, Chongqing University of Arts and Sciences, Chongqing, \\ China; ${ }^{*}$ Corresponding Author: gy8620@163.com \\ ${ }^{2}$ Chongqing Yongchuan Middle School, Chongqing, China.
}

Received 3 May 2011; revised 19 June 2011; accepted 28 June 2011.

\begin{abstract}
Purpose: To explore the interventional effects of campus psychodrama on improving the interpersonal trust among college students. Methods: 16 college students with low levels of interpersonal trust were selected to conduct 5 sessions of psychodrama therapy. Results: The subject group has gone through stages of ice breaking, performance, and sharing. Through group counseling with psychodrama, the social avoidance and distressful behaviors of the subjects have been alleviated, and their levels of interpersonal trust demonstrated notable change. Conclusion: Campus psychodrama is an effective group counseling approach for improving college students' interpersonal trust.
\end{abstract}

Keywords: Psychodrama Therapy; Interpersonal Trust; Group Intervention

\section{INTRODUCTION}

Along with the reform and opening of China, the people's values have become diversified, and the social morphology and family structures have undergone dramatic changes. In this context, college students are confronted with pressures from various sources, and suffer from psychological perplexities and disorders to different degrees. Perplexity in interpersonal relationships is a key contributor to their mental troubles, and interpersonal trust serves as important metric measuring interpersonal relationships. Interpersonal trust refers to a positive psychological anticipation regarding other's reliability of their words and promises in the process of interpersonal interaction, and its current conditions are not optimistic[1,2]. As to the foregoing problems, research- ers have tried various group counseling methods for treatment and have positively explored the effects of the novel expressive art therapy $[3,4]$.

Psychodrama helps individuals present their psychological problems, which was proposed and developed by a Vienna psychiatrist J. L. Moreno [5]. Psychodrama incorporates individuals' cognitive analysis, practical experience, participation and immersion, and features group therapy. During interaction among group members, physical activities of participants make them sense their innermost needs and desires. Campus psychodrama, which was first developed between late 1980s and early 1990s, is a manifestation of psychodrama with Chinese campus characteristics developed in campuses after it was introduced into China and applied by some psychological health education experts in education practices. Psychodrama combines drama, sketches and psychological problems. It advocates spontaneity and authenticity of actors' performance. It is a method of group psychological therapy in which students can learn how to face and correctly tackle with psychological problems so that they can solve their own psychological problems and give educational inspiration to all participants with the help of psychological counseling teachers and all participating actors, through playing roles of themselves or presenting all kinds of typical psychological problems on the stage. According to related existing practices, performing psychodrama helps facilitate positive changes of unhealthy emotions and behaviors during interpersonal interaction [6].

The study uses campus psychodrama and focuses on improving college students' interpersonal trust through campus psychodrama intervention tests to explore the effectiveness of campus psychodrama in improving college students' interpersonal trust. 


\section{METHOD}

\subsection{Design of Study}

The study uses two groups in the design of pre- and post-test, with one being the experimental group and the other being the control group. Before and after the test, subjects of both groups received the same psychological assessment respectively together with qualitative indepth interviews and case analysis.

\subsection{Participants}

150 sophomores and juniors were randomly selected from a university and went through the assessment with the Interpersonal Trust Scale and the Social Avoidance and Distress Scale. The 32 students whose scores of "interpersonal trust" are lower than 72 and those of social avoidance and distress are among the highest were selected. Based on their willingness, they are assigned to the experimental group and the control group, with 16 students in each group.

\subsection{Measures}

The Interpersonal Trust Scale (ITS), prepared by Rempel and Holmes (1986) [7], contains 18 questions involving the three dimensions of trust: predictability, dependability and reliability. Predictability refers to the possibility whether we can predict our partners' specific behaviors, including those welcomed and unwelcome ones. Dependability is the core of trust, while reliability drives people to believe their partners will carry on responsibility to take care of them. 7-point rating style is adopted in the scale, in which 1 point = totally disagree and 7 points = totally agree. Total scores range from 18 points (lowest credibility) to 126 points (highest credibility) with a median of 72 points, higher scores indicating higher credibility. The scale is of good reliability and validity that values of homogeneity reliability are 0.81 , 0.82 and 0.80 respectively in sub-scales. The three sub-scales are moderately correlated (ranging from 0.27 to 0.46).

The Social Avoidance and Distress Scale (SAD) formulated by Watson and Friend (1969) [7], refers to distress in personal experience of social avoidance. Avoidance is a behavior while distress is an emotional response. It contains 28 items with 14 items for evaluating social avoidance and the others for evaluating social distress. Method of "yes or no" is adopted. Quite high internal consistency shows itself when the method is adopted, that average correlation coefficient of average and items is 0.77 and retest reliability is 0.68 . When 5-point rating style is used, The Cronbach's Alpha coefficient for internal consistency reliability is close to 0.90 .
Plan of group counseling with campus psychodrama.

\subsection{Processing of Experimental Data}

Classify and number the pre-test and post-test of each participant's scale according to the type of groups and make statistics and analysis with SPSS13.0. Qualitative analysis was used for subjective evaluation.

\section{RESULTS}

\subsection{Procedure and Analysis}

The participants of the experimental group received courses of intervention activities from the campus psychodrama workshop, while the participants of the control group did not take part in the intervention activities and go on other activities as usual. The procedure is described as follows:

The intervention activities of campus psychodrama were held for 5 sessions, one session a week, and each session lasted for 2 hours. Each session included three stages.

Ice breaking stage: A short time of greeting and communication and some warm-up games were made to create a good psychological atmosphere within the group.

At the beginning of each session, under guidance of the group leader, group members played different interpersonal trust games and created a friendly, trustful group atmosphere so that members could interact actively with each other and express themselves and share their feelings [8].

Performance stage: sharing of experiences and performance based on the preset themes.

Group members chose seats they like and then sat down in a circle. Then the group leader, as the first one, shared his/her own story in his/her life. The story, not judged for good or evil, right and wrong, only aimed at releasing emotions and fostering communication. In the process of performance, the most important thing was not acting skills but finding causes of problems when scenes reappeared, finding solutions and unlocking mental knots to release emotions and heal wounds, and to inspire oneself and spectators $[9,10]$.

Sharing stage: Getting away from roles, reviewing and concluding.

With help from the audience or the group leader, the actor/actress came out from his/her role with his/her physical and mental state realigned, to make himself/herself understand his/her role and be ready for the closure of the courses. The students exchanged ideas about the contents of performance by turn, shared their feelings and gave regards and recognition to themselves 
or others. Then the group leader commented on the activity briefly and gave students some encourage, then issued questionnaires to collect information about students' feelings and gains in the activities and about their suggestions toward next session. Information collected in this stage would be auxiliary materials in addition to the quantitative study and be used in qualitative study analysis.

\subsection{Results and Analysis}

\subsubsection{Changes in Quantitative Results}

Pre-test and post-test assessments were conducted for the experimental and the control group. In order to eliminate the impact of the pre-test scores, post-test scores (post-test scores of the Interpersonal Trust Scale and the Social Avoidance and Distress Scale) were taken as the dependent variables; groups (experimental group and control group) were the independent variables; pre-test scores were the concomitant variables. The pre-test scores were used to make analysis of covariance and check whether the slope of each group was equal to others. The results revealed that the interaction effect between groups and its corresponding pre-test scores (scores got from two scales) was insignificant $(\mathrm{F}=0.082$, $p>0.05 ; \mathrm{F}=3.465, p>0.05$ ).

For the control group, scores of the tests before and after the test had no difference. For the experimental group, the total score of the Social Avoidance and Distress Scale and scores of the elements after the test were lower than those before the test, but having no statistically significant difference; the total score of the Interpersonal Trust Scale and scores of the elements after the test increased considerably and there were significant differences between the total score and scores of predictability and reliability before and after the test $(p<0.01$, $p<0.001$ ). During the post-test, there existed significant differences in the total score and scores of predictability, reliability of the experimental group and those of the control group for Interpersonal Trust Scale $(p<0.05, p<$ 0.01) (Table 1).

\subsubsection{Results of Qualitative Analysis}

Conditions of the experimental group members throughout the activities were observed and recorded. Some members were sampled to answer questionnaires at the end of each session. Then the group leader and group members discussed the activities and exchanged ideas based on the preset theme. During interval of two activities, members were randomly selected to complete brief interviews through the Internet or by phone to know their feelings.

According to observation of researchers and feedback of participants, examples of the results are described below:

1) Positive effect on interpersonal trust:

"I think people around me love me, and this feeling is so good!"; "We are like old friends, and we feel so close to each other."

2) Reduced social distress and avoidance:

"I begin to enjoy playing games with others.”; “Actually, staying with male students is not so suffering."

3) Breakthroughs in understanding of themselves and the society:

"Wherever we are, it is not a lack of beauty of life, but it is our lack of discovery. I'm never a blind person!!!”

"I find sense of existence and I find that everyone is

Table 1. Scores of experimental group and control group during pre-test and post-test of college students' interpersonal trust.

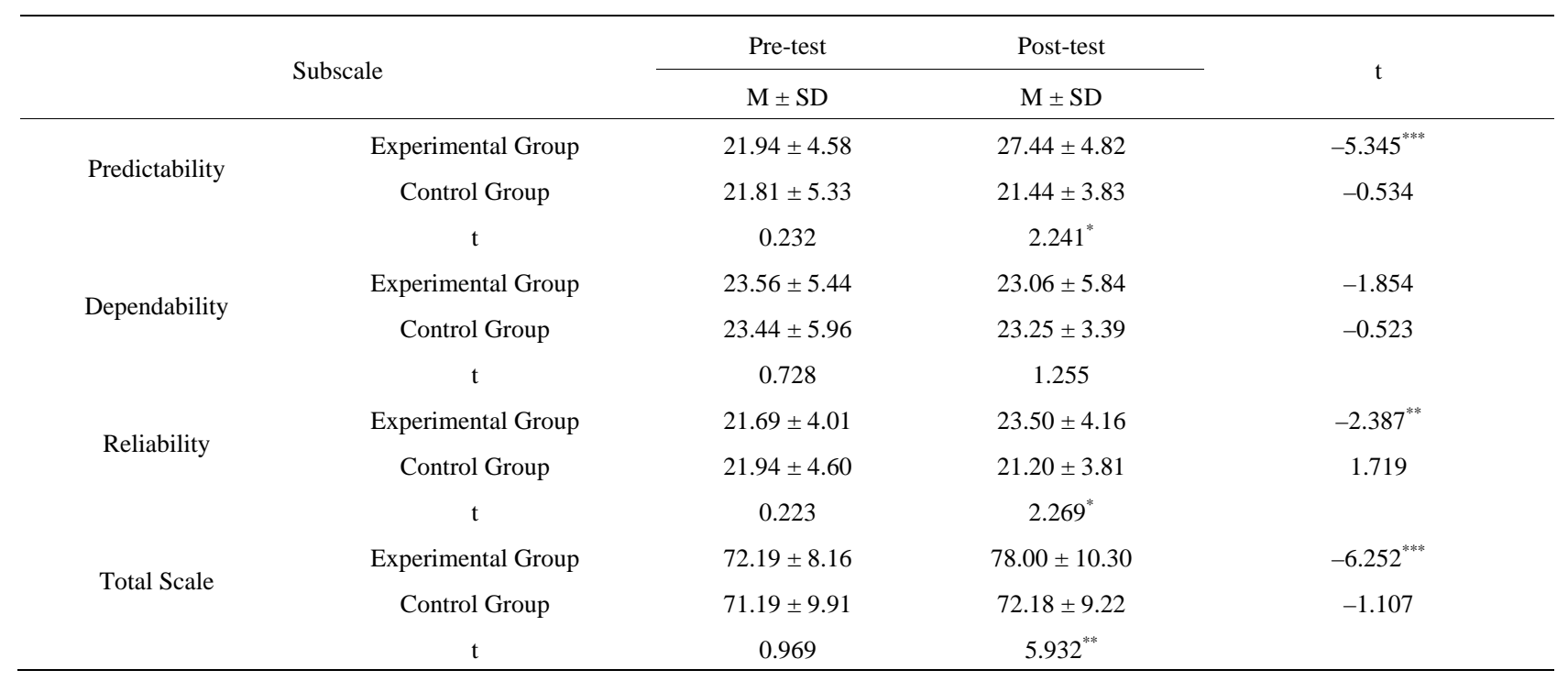


Note: ${ }^{*} p<0.05 ;{ }^{* *} p<0.01 ;{ }^{* * *} p<0.001$.

paying attention to me, which makes me become confident and do something energetically.”

4) More positive emotional experience:

"I am potential, and I have abilities to care and help others."

"In fact, hurt sometimes can make people grow and act as an alarm bell which reminds me and spurs me on not doing the same things.”

\section{DISCUSSION}

\subsection{Quantitative Data Analysis}

From the general findings of the study, the participants of the experimental group after the campus psychodrama intervention have improved their interpersonal trust level and reduced social avoidance and distress. Compared with the control group, the experimental group shows significant differences in the total scores of interpersonal trust and those of predictability, reliability. In the early stage, the group members had low interpersonal trust levels, and they rarely participated in group activities. However, group life is essential to the growth of human beings, and the growth of individuals has close relationship with development of their groups. If one person loses communication opportunities with others for long period, feelings of emptiness, depression and disappointment will haunt him/her. As a result, his/her interpersonal trust level can not be improved and would even be degraded [11,12]. The campus psychodrama workshop established a group, providing a platform for those students with low trust levels to develop their interpersonal skills and giving them an emotional experience of happiness in activities.

Predictability in the Interpersonal Trust Scale refers to the capability of predicting specific behaviors of our peers, including both the favorable and unfavorable behaviors. Reliability refers that people can unconditionally trust that their companions will continue to take responsibility and care for them [7]. The experimental group made remarkable improvement in the results on these two dimensions. These results indicate that campus psychodrama played a positive and contagious role by providing an opportunity and a platform to change participants' cognition through experiencing emotional feelings or behavior reactions with spontaneous and voluntary performances of participants [13]. First of all, it creates an interactive scene, in which the parties in the campus psychodrama can play freely without the restriction in the real life situations. Secondly, psychodrama has similarity with the specific situations in the campus life, so mental troubles can be revealed one by one along the development of the plot. Characters in the play can easily get rid of obstacles, and express and act naturally because they are immersed by the scenes. Furthermore, there are no criteria of right or wrong in performing, but tolerance, understanding and enlightenment. There are no requirements for acting skills but emphases on participation and self-expression. Under the atmosphere of appreciation and understanding, members are led to express and feel different kinds of interpersonal experience openly, break the border of possibility or impossibility, right or wrong and beauty or ugliness from the original concepts and experience more enjoyment of success. Certainly, such performance and acceptance are not purposeless, for group counseling has its educational goals to help members build correct cognition, attitudes and behaviors by teaching them how to obtain right information, driving them to discuss the possibilities of conflict settlement and leading them through important experiences of life. The group provides scenes for the members to try new behaviors and change their existing behaviors. The group also tries to help rectify the members [12]. The campus psychodrama workshop creates a safe, open and tolerate group and guides members to observe in the group, get familiar with habits of the group and feel the care from the group. Meanwhile, it helps members get rid of misconduct, learn new and effective behavior patterns, improve interaction with people, and reduce social avoidance and distress.

\subsection{Qualitative Mechanism Analysis}

1) Enhance self-awareness and perceiving for things during the performance.

Performance is the demonstration and epitome of the human nature. During the intervention process of the test, members conducted purposeful performances which also happened in real life on the stage. There were no right or wrong criteria, and the performers were able to perform and interpret the plays freely. Experiencing helped them get rid of unfavorable feelings such as distrust, boredom, helplessness and sadness, and establish a group of mutual assistance, pleasure, dynamics, enlightenment and trustworthiness. After the group entered the work (performance) phase, the group leader changed from an active guide to a facilitator, supporter and data provider behind the scenes, in order to make individuals know more clear about their own behaviors and change their behaviors. The group experience provided members with the opportunity of discussing different ways for solving problems, made members feel the insights from their emotional release in the performance and enhance their understanding of themselves and the surroundings [14,15].

2) Role reversal and metal position conversion.

During the performance, each group member drew 
others' attention and care about theirs, as they appreciated their own emotion and thought about that of others. The role reversal made the members reconsider events in their life in different roles. A healthy interpersonal relationship was formed in the role-play, because the performer experienced the joys and sorrows of the role's inner world, his/her metal position was conversed, put themselves in others' shoes to explore their behaviors in depth and the impact of their behaviors on others, with improved mutual understanding of roles[16] .

3) A favorable atmosphere among group members allowing alternative experiential learning.

In the group context, the emotional and interactive ties among members not only influenced the development of the group but also stimulated members to be more open. In the group's harmonious atmosphere, members identified each other and developed a sense of intimacy and dependence, allowing the members to learn how to adjust their mood through proper use of reasoning, transfer, sublimation and catharsis, improve the communicative methods positively, and correctly express their favorable impression of others, listen attractively to others and exchange their mental transposition [17].

In the study, the campus psychodrama workshop provided the participants with problem solutions from various perspectives in an atmosphere of tolerance, acceptance and support, and avoided confinement to limited perspectives and stereotypes. Participants were enabled to freely and actively identify mature and effective ways from activities to deal with problems, help each other, release or control emotion, gradually learn new behaviors through imitation, and finally try to migrate the new behaviors into the real life [18].

\section{CONCLUSIONS}

The scores on the dimensions of predictability, reliability and on the total scale of interpersonal trust have improved significantly. Results have shown that campus psychodrama is an effective approach of group counseling for improving the interpersonal trust of college students and positively reducing their social avoidance and distress.

\section{ACKNOWLEDGEMENTS}

This study was supported by the fund of College Students Experimental Project "Intervention Study of Education and Counseling with Campus Psychodrama” at Chongqing University of Arts and Sciences (200921).

\section{REFERENCES}

[1] Zhang, J. (2008) Study on characteristics of college students' interpersonal trust and loneliness. Master's Dissertation, Chongqing University, Chongqing.

[2] Zhou, J. (2007) Study on conditions of college students' interpersonal trust and related issues. Master's Dissertation, Zhengzhou University, Zhengzhou.

[3] Lin, S.Q. (2002) Study on counseling with music therapy activities for attacks by fourth to sixth graders of elementary schools and their interpersonal relationship. Master's Dissertation, Psychological Counseling Education Institution of Pingtung Teachers' College, Taiwan.

[4] Cao, Z.L. (2007) Study on impact of teaching with game activities on interpersonal trust to sixth graders of primary school. Master's Dissertation, South China Normal University, Guangzhou.

[5] Blatner A. (2004) Acting-in: Practical applications of psychodramatic methods. Psychology Press, Taibei.

[6] Deng, X.Y., et al. (2009) Theory and nazctice of psychodrama and situation play. Chemical $\overline{\overline{\bar{V}}}$ stry Press, Beijing.

[7] Wang, X.D. (1999) Score scales for mental health. Chinese Mental Health Journal, 144-146.

[8] Xu, G.X. (2007) Mental case collection of children game therapy. Shanghai Education Press, Shanghai.

[9] Shi, H. (2006) Piratical handbook of psychodrama and situation play. Beijing Normal University Press, Beijing.

[10] Division of Jiangxi Education Department (2009) Dancing with heart - operation manual of campus psychodrama. China Renmin University Press, Beijing.

[11] Zhang, X. and Wang X.F. (2003) The factor analysis of interpersonal trust and interactive anxiousness of contemporary college students - Nanchang as the investigative center. Journal of Jiangxi Normal University (Philosophy and Social Science Edition), 36, 78.

[12] Xu, X.S. (2003) Group dynamics and group counseling. World Publishing Guangdong Corporation, Guangzhou.

[13] Wang, W.P. (2009) Campus psychodrama-An effective method of psychological education in colleges and universities. Social Sciences Journal of Colleges of Shanxi, 5, 105-107.

[14] Zhang, W. (2007) Test-based study on group psychological counseling with dances for development of mental health of college students. Doctoral Dissertation, Beijing Normal University, Beijing.

[15] Wu, W.D. (2009) Principles of psychological counseling at school. World Publishing Guangdong Corporation, Guangzhou.

[16] Huang, X.Y., et al. (2003) Study on campus psychodrama. Suzhou University Press, Suzhou.

[17] Fan, F.M. (2007) Group counseling. Higher Education Press, Beijing.

[18] Moreno, Z.T. (1989) Psychodrama, role theory, and the concept of the social atom. Journal of Group Psychotherapy, Psychodrama and Sociometry. 42, 178-187. 